Original Research

\title{
Multi-Disciplinary and Multi-Scale Assessment of Marine Renewable Energy Structure in a Tidal System
}

\author{
Aurore Raoux *, Ilan Robin, Jean-Philippe Pezy, Anne-Claire Bennis, Jean-Claude Dauvin
}

Normandie Univ., UNICAEN, Laboratoire Morphodynamique Continentale et Côtière M2C, UMR 6143 M2C, 24 rue des Tilleuls, F-14000 Caen, France; E-Mails: raoux.aurore@gmail.com; ilan.robin@unicaen.fr; jean-philippe.pezy@unicaen.fr; anne-claire.bennis@unicaen.fr; jeanclaude.dauvin@unicaen.fr

* Correspondence: Aurore Raoux; E-Mail: raoux.aurore@gmail.com

Academic Editor: Andrés Elías Feijóo Lorenzo

Special Issue: Renewable Energy in Marine Environment

Journal of Energy and Power Technology

2021, volume 3 , issue 1

doi:10.21926/jept.2101012
Received: October 08, 2020

Accepted: March 05, 2021

Published: March 17, 2021

\begin{abstract}
The French coast of the Atlantic and English Channel (EC) is promising for the development of Marine Renewable Energy (MRE), including wind, wave, and tidal stream, due to the high velocity of currents in some parts of the area. This paper, focusing on wind and tidal energy, discusses how the implementation of MRE converters influences biodiversity, and vice versa, through biofouling and reef effects. The understanding of these interactions requires the knowledge of the hydro-sedimentary conditions and the macrofauna. The research on these topics, performed at the Continental and Coastal Morphodynamic laboratory (M2C) (UNICAEN, France), is presented through a multi-disciplinary approach by i) studying the hydrodynamic conditions and the macrofauna in Alderney Race, ii) studying the biofouling effects on tidal turbines and their influence on the turbulent wake, iii) assessing the hydrosedimentary impacts induced by the offshore wind farm, like scouring, and iv) taking an ecosystem approach on MRE, such as the reef effect. From an ecological perspective, the reef effect can be responsible for changes in the structure and function of the ecosystem. Although several studies have analyzed this effect at the species-or community-scale, the propagation
\end{abstract}

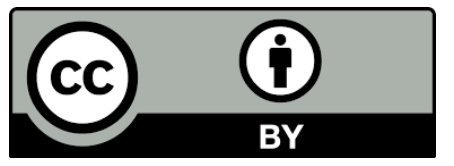

(c) 2021 by the author. This is an open access article distributed under the conditions of the Creative Commons by Attribution License, which permits unrestricted use, distribution, and reproduction in any medium or format, provided the original work is correctly cited. 
of the reef effect at the ecosystem-scale remains unclear. Thus, understanding these ecosystem-scale effects is urgent for future research. From an engineering perspective, biofouling changes the structural characteristics (i.e., supplementary mass) of the converters and thus, affects their performance.

\section{Keywords}

English Channel; Alderney Race; energy characterization; environmental impacts; fluidstructure interaction; tidal turbine; offshore wind farm; biofouling effect; reef effect

\section{Introduction}

The European Union (EU) had set a target to derive $20 \%$ of its consumed energy from renewable energy sources by 2020. With more than 11 million $\mathrm{km}^{2}$ of water under its jurisdiction, France holds a huge potential for marine renewable energy. Currently, the construction of eight anchored offshore wind farms (OWFs) and four floating OWFs has been planned in metropolitan France (Figure 1). Among them, five anchored offshore wind farms will be built on the English Channel.

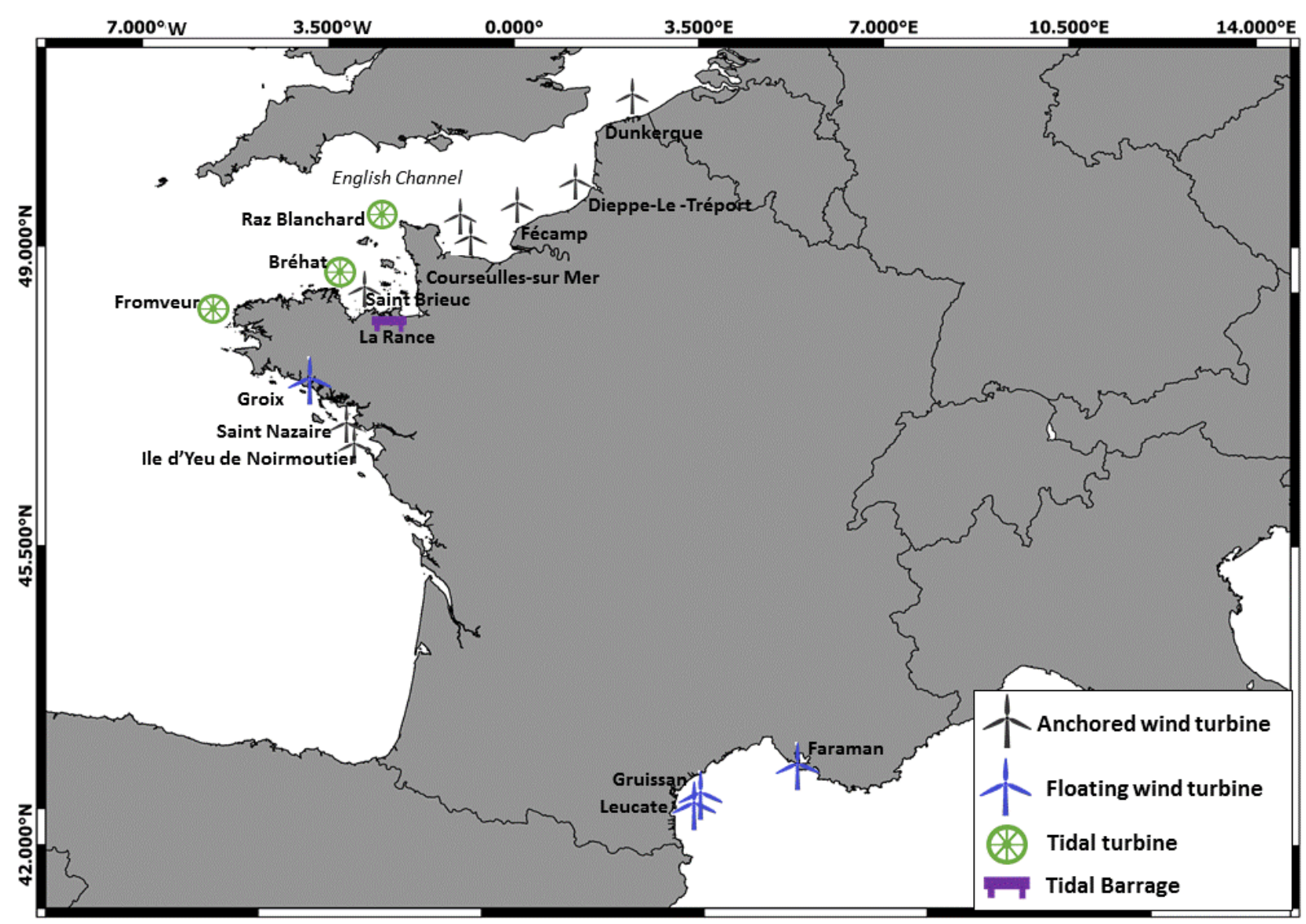

Figure 1 Marine renewable energy development along the French metropolitan coast.

Till the end of 2020, no OWFs have been constructed due to the long administrative procedures and numerous appeals in courts at the French and the European levels [1]. Nevertheless, several 
studies have been performed to identify the environmental conditions and ecosystem functioning in selected sites before the implementation of OWFs. These surveys considered several biological groups, including macrobenthos, fish, birds, and mammals (including bats), while assessing the quality of seawater and hydro-sedimentary conditions.

Tidal energy is complementary to wind energy. The tidal power in Europe is estimated at 10 gigawatts (GW), with $4 \mathrm{GW}$ in France. French tidal energy sites are located in Brittany (Fromveur and Bréhat) and Normandy (Raz Blanchard) (Figure 1). The site with the highest tidal energy is the Alderney Race (Raz Blanchard) (3 GW). However, it is also the most complicated site due to complex hydrodynamics, with strong tidal currents (up to 12 knots), ocean waves, highly-energetic turbulent cells, and an uneven sea bed with different geological features (e.g., submarine faults, pebble dunes, etc.). Ten turbine-farms should be installed in Alderney Race to obtain a total power of $20 \mathrm{MW}$. The first French tidal turbines were connected to the electrical network in 2019 in the Ushant Race at Fromveur and at Bréhat (Figure 1).

In the last decade, research laboratories at the University of Caen Normandy had invested in renewable energy development in the marine environment, especially in the Normandy territory at the western part of the English Channel, in the north of Cotentin in the Raz Blanchard area, and the eastern part of the EC in the extended Bay of Seine.

The Continental and Coastal Morphodynamic laboratory (M2C) had developed multi-disciplinary approaches, such as in situ observations, high-frequency radar measurements, physical experimentations, trophic food models, and numerical modeling (Figure 2). The challenge was not only to accompany the development of MRE for each scientific discipline but also to share expertise and develop common projects on ecosystem functioning. This could be achieved by using physical and numerical modeling at different scales of observations, ranging from the consequences of biofouling of tidal turbines on energy production to the regional suspected impacts of offshore wind farming. Although previous studies have highlighted that the colonization of MRE structures by marine species (also called biofouling) can be responsible for both ecological and engineering consequences, its effects at the ecosystem-scale and on the performance of the offshore infrastructure remain poorly understood. Using a multi-disciplinary approach comprising benthos ecology, trophic web, and numerical modeling, along with expertise on the characteristics of the EC, the $\mathrm{M} 2 \mathrm{C}$ laboratory can make an important contribution to the understanding of key issues surrounding the MRE in the EC. The EC is a coastal sea with a strong tidal regime and dominant western winds, which ensures large-scale electricity production in the future. Notably, the M2C is also a member of the Working Group on Marine Benthal and Renewable Energy Developments (WGMBRED), a part of the International Council for the Exploration of the Sea (ICES), since 2013. Thus, this paper aims to present the progress of our research in the development of MRE in the EC. 


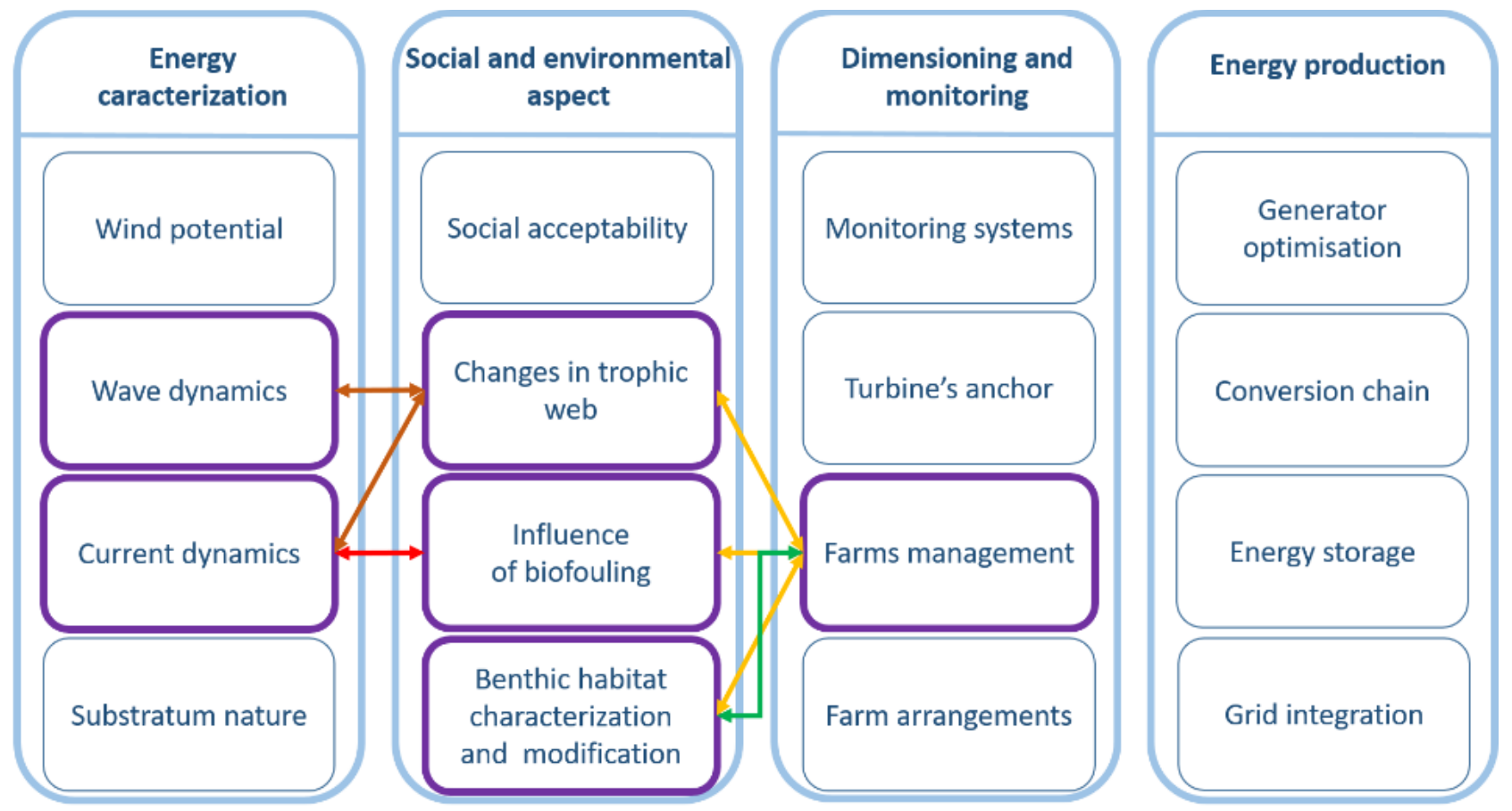

Study of the impact of biofouling on tidal turbine performances

Study of wave and current dynamics in order to study the impact on local ecosystems

Study of the impact of wind turbine farms on the local ecosystem

Study of local ecosystems before farm implantation

$\mathrm{M} 2 \mathrm{C}$ interest fields

Figure 2 Multi-disciplinary approaches developed by the Continental and Coastal Morphodynamic laboratory (M2C) on MRE.

\section{Context: The English Channel, a Megatidal Sea}

The English Channel (EC) is a shallow epi-continental sea shared between the United Kingdom in the north and France in the south, with a maximum depth of $174 \mathrm{~m}$ in the Hurd Deep (150 km in length and 1.5 to $5 \mathrm{~km}$ in width) (Figure 1) [2]. Its western basin is deeper than the Eastern basin and is influenced by the Atlantic waters. It shows the presence of a summer thermocline offshore Plymouth, while the eastern basin is mainly affected by the input of freshwater from the Seine River. The tidal regime is dominated by semidiurnal tides with a period of $12 \mathrm{~h}$ and $25 \mathrm{~min}$. The tidal ranges are greater along the French coast, mainly in the Mont-Saint-Michel Bay than along the British coast. The tidal residual propagates from the west to the east, with a water replacement time of approximately 500 days. Due to the Coriolis force, current velocities are higher along the French coast than the English coast, reaching greater than three knots in north Brittany, off the Cotentin Peninsula. In the Dover Strait, velocities exceed eight knots off the Cap de La Hague. Significant gyres are present around the Channel Islands and to the east of the capes of Fréhel, Barfleur, Antifer, and Gris Nez. Tidal currents dominate sedimentation processes; extensive pebbly sediments dominate areas of strong tidal currents located offshore and to the east of the capes, whereas fine sands and muddy fine sands appear in areas of weak tidal currents in bays and estuaries. Coarse sands and pebbles cover more than $80 \%$ of the EC seabed area; another particular feature of the sediments is their high proportions of calcareous biogenic material, reaching up to $80 \%$ in the bioclastic sediments in the central part of the western EC [2]. Located between $48^{\circ} 30^{\prime} \mathrm{N}$ and $51^{\circ}$ 
$10^{\prime} \mathrm{N}, \mathrm{EC}$ is a temperate sea and is a biogeographical transition zone between the Lusitanian and Boreal provinces, influenced by a balance between warm, temperate species during warm periods and boreal species during cool periods [2].

Moreover, the EC is among the most active coastal marine zones where cumulative human impacts are the greatest. The eastern basin is more impacted than the western basin due to widespread traditional activities such as maintenance of fisheries and the emergence of new activities such as granulate extraction and offshore wind farm installations [2, 3].

\section{Hydrodynamic conditions in Alderney Race}

To determine the shear of surface currents and sea states, high-frequency (HF) radars were implemented in Cap de la Hague in 2017. They monitored in real-time the surface hydrodynamic (currents and sea states). This innovative system, using two transmitting frequencies $(24.5 \mathrm{MHz}$ and 13.5 $\mathrm{MHz}$ ), produced rare data of the spatialized hydrodynamic of the Alderney Race. First, these data have enabled validation of the numerical model (3D-fully wave-current model); for surface currents, a good agreement has a Root-Mean-Square-Error between 14 and $40 \mathrm{~cm} / \mathrm{s}$ for the neap tide and between 18 and $60 \mathrm{~cm} / \mathrm{s}$ for the spring tide [4, 5]. Maximum errors were found in shallow zones with consistently high current velocities. Second, some regions with a strong current shear were highlighted in the radar data; a new methodology for the radar data analysis in such regions is under development.

In addition to the HF radar measurements, some efforts in numerical modeling were performed during HY2DM. An innovative Large Eddy Simulation (LES) method, called LANS-alpha, was implemented in a coastal hydrodynamic numerical model, MARS3D [6], to improve the simulation of the marine turbulence $[7,8]$. This method differs from the classical dissipative LES in that this is a reformulation of the equations of fluid mechanics with alteration of the existing non-linear terms and the addition of extra non-linear terms. LANS-alpha does not use a sub-grid scale viscosity, unlike dissipative LES. After a validation step for a wind-driven motion over a seamount, this method was applied to the Alderney Race. A re-energization of the flow was observed with two types of turbulence energy decay in the inertial zone as expected for two-dimensional turbulence. This method mainly affects the turbulence induced by deformation; rotation-induced turbulence is slightly modified. The computing time is reduced by $30 \%$ by the use of LANS-alpha.

Furthermore, $\mathrm{M} 2 \mathrm{C}$ researchers studied the impact of the wave-current interactions on the tidal stream energy using numerical modeling. The 3D-fully wave-current simulations were performed with the coupled model, which combined the hydrodynamic numerical model, MARS 3D, and the spectral wave model, WAVEWATCH-III [9]. Data from this coupled model were tested and compared with in situ observed data and were found to have good scores [10]: i) the RMSE related to the sea level was around $0.13 \mathrm{~m}$ and $0.44 \mathrm{~m}$ at Cherbourg and Dièlette, respectively, ii) the PBIAS (percent bias) related to wind at ten-meters height was around $10 \%$ and lesser than $4 \%$ for magnitude and direction, respectively, iii) the significant wave height PBIAS was around $6 \%$ with an $\mathrm{R}^{2}$ (coefficient of determination) of 0.97 , iv) the NRMSE (Normalized RMSE) related to the magnitude of current was around 0.11 . The inclusion of wave effects has contributed to a decrease in the error in tidal energy estimate, which was lesser than 10\% for the considered time-period (21-25 November 2017). Additionally, the impact of Eleanor's storm (on 2-3 January 2020) on tidal energy was simulated using the coupled model. This storm occurred during a spring tide. A strong reduction in tidal current 
magnitude (0.4-0.5 m/s) was observed with PBIAS reduction by a factor of 1.89 and 1.76 for simulations with only tides and with both tides and wind, respectively [11].

\section{Macrofauna in the Alderney Race}

In the research project entitled "Pile \& Tide", financed by the ADEME (Agence de l'Environnement et de la Maîtrise de l'Energie), the $\mathrm{M} 2 \mathrm{C}$ laboratory was in charge of the investigation of the benthic habitats (seabed composition and benthic communities) in the Alderney Race strait. The area is located in the western basin of the English Channel to the North of the Normand-Breton Gulf, with the strongest tidal currents in Europe. The water depth here varies between 20 and $80 \mathrm{~m}$. The sea bed is mainly composed of granite and calcareous rocks of the Cambrian, Silurian, and Cretaceous ages; some surficial sediments in small patches between rocky substrate are mainly composed of gravel and pebbles [12].

The data on the macrofauna of such a dynamic area are very rare and were obtained in the 1970s from the doctoral thesis of Retière (1979) [13], who described a mussel community, Musculus discors (L., 1767), in the area of the Alderney Race. Additionally, the horse mussel, Modiolus modiolus (Lamarck, 1799), was reported to form mussel beds. However, M. modiolus was not recorded recently in samplings in 2015-2016 [12], and its persistence in this area, which corresponds to the southern limit of its distribution in the north-eastern Atlantic, needs to be confirmed

During three sampling campaigns between 2015 and 2016, a total of 38 benthic stations were visited with a Rallier du Baty dredge. A single gear was used to sample the sea bed in hydrodynamic areas. Of the 38 operated dredges, 24 were unsuccessful, containing little to no sediments, and only 14 yielded sufficient volume of sediment ( 0.5 to $32 \mathrm{~L}$ ) composed of gravels and pebbles with or without sessile epifauna [12]. Despite a low number of effective stations, the collected fauna showed high diversity with 140 different taxa, dominated by crustaceans ( 69 taxa). The fauna was characterized by small species living either in interstitial positions, or as infauna, or protected (like erect hydrozoans). Most of the sampled species were adapted to live in high-energy hydrodynamic conditions and hard irregular sea beds. Following Michez et al. (2015) [14], three benthic habitats were identified [12]: (1) very mobile and coarse infralittoral sediments with scattered fauna; (2) circalittoral pebbles under strong hydrodynamic conditions with scattered fauna; and (3) mobile coastal circalittoral gravel and pebbles consisting of Spirobranchus triqueter (L., 1758), barnacles, and encrusted bryozoans. New locations of two crustacean species in the English Channel were reported for the amphipod, Elasmopus thalyae (Gouillieux and Sorbe, 2015) [15], found at the soft and hard bottoms of the Arcachon Bay [16] and the tanaid, Zeuxo holdichi (Bamber, 1990), described from the Arcachon Bay [17].

To provide additional information to standard benthic observations, Foveau et al. (2017) [18] had developed a new underwater imagery system to monitor the seafloor and benthic communities of the Alderney Race. Despite the difficulty in the acquisition, the underwater images highlighted the heterogeneous nature of the seabed in the Alderney Race. A total of 380 photos of the seafloor were obtained during a 2016 survey, among which 38\% were usable [18]. Two main sediment types were recognized: (1) gravel and blocks, mixed in a more or less cohesive way, and (2) bedrock. Sessile fauna was identified from the images, which included the barnacle, Balanus crenatus (Bruguière, 1789), hydrozoans belonging to the genus Sertularia, as well as poriferans and 
bryozoans. From the images, it was not possible to determine mobile species due to their small size and infaunal lifestyle.

In summary, the sea bed was mainly composed of a hard bottom with small enclaves of coarse sediments in the spaces between large granite blocks. This area remained difficult to explore due to its high heterogeneity and steep slopes (in some places, the vertical depth varied by $10 \mathrm{~m}$ over a horizontal distance of $5 \mathrm{~m}$ [18]). Due to strong currents, the hard bottom was poorly colonized by sessile fauna, except the mussel, Musculus discors, and the barnacle, Balanus crenatus, which dominated the epifauna. Nevertheless, the infauna was rich and consisted mainly of small species adapted to live in clean mobile sediments.

\section{Impact of Macrofauna on Tidal Turbine Performances}

After identifying the macrofauna of the Alderney Race, the $\mathrm{M} 2 \mathrm{C}$ researchers investigated its influence on the tidal turbine performance. In particular, the effects induced by biofouling on the turbulent wake were studied. Assessing these effects is a relevant issue for the tidal industry to minimize the maintenance of the turbines. Numerical modeling is challenging due to the need to solve the geometry of biofouling species in the mesh and to produce long time series for the diagnosis of turbine performance. Computational Fluid Dynamic (CFD) simulations were carried out to understand how species changed the flow near the blades using three main types of turbulence models (RANS, LES, DNS) available in OpenFoam [19]. The computational domain was composed of two meshes-one was fixed, while the other rotates and contained the rotor. The Arbitrary Mesh Interface (AMI) method was used to send the flow from one mesh to the other. As explained in Figure 3, the LES (Large Eddy Simulation) method with the Smagorinsky model was the best choice for this application; turbulent structures induced by biofouling were better represented than using RANS, and the computing time was less than using the DNS model. The simulated turbulent wake was found to be sensitive to the presence of organisms. When the colonization was located near the leading edge, the effects were much more significant. Moreover, a single organism or a small colony can disrupt the wake more than a large colony, leading to a sharkskin effect. Threedimensional effects were also investigated by Robin et al. (2019) [20] for the cases of forced and flow-induced rotations. Flow-induced rotation conforms to the energy chain better than forced rotation. In flow-induced rotation, the primary energy contained in the flow is transformed into mechanical energy before being converted into electricity. The wakes in both cases were compared, and, as expected, the signals were similar for similar speeds of rotation. It showed that flow-induced code does not interfere with the flow results. Moreover, biofouling modifies the rotor weight, which mainly affects the turbine's behavior when the flow strongly depends on time. The modification of the mass impacts the rotor's restart (transition mode) if it is heavily loaded with organisms. This problem was unlikely to occur in the Alderney Race but can appear at tidal turbines in shallower seas. The $\mathrm{M} 2 \mathrm{C}$ researchers are currently working on the coupling between OpenFoam (CFD) and Dorothy (vortex model) numerical codes to reduce the computing time. OpenFoam will handle the close-blade field while Dorothy will solve the wake in the far-field. Thus, we will have an efficient tool to study the impacts of different colonizations on the performance of the tidal turbines. 


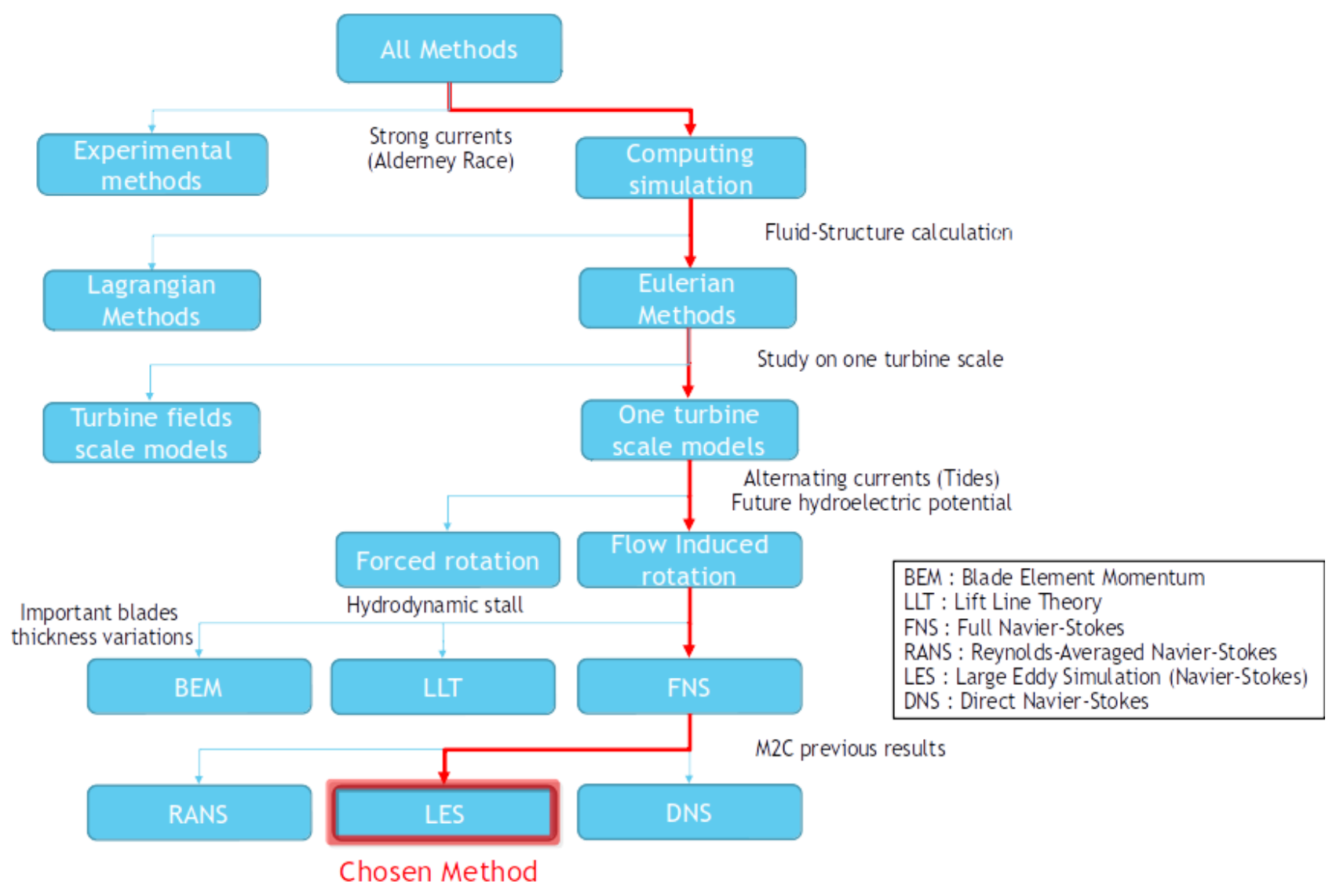

Figure 3 Decision tree for CTD method selection.

\section{Assessment of the Environmental Impacts of the Offshore Wind Farm Foundations}

In the Ofelia project (Interreg IVa France-England), the M2C was in charge of the numerical modeling for the assessment of the hydro-sedimentary impacts of the monopiles on the future Courseulles s/mer wind farm [21, 22]. A subgrid-scale parameterization was developed and implemented in the three-dimensional hydrodynamical model, MARS 3D. This parameterization, based on Ganthy (2011) [23] and Kombiadou et al. (2014) [24] for the Zostera noltei meadows, was able to reproduce the changes in the flow due to the monopiles and the impacts on the seabed morphology by adding drag forces to the momentum and turbulence equations. Comparisons with simulations where the monopiles were explicitly solved in the mesh were done to evaluate the performance of the parameterization over a tidal cycle. We observed similar behaviors between the two types of simulations, where currents increased at the side of the monopile and decreased in front and downstream of the monopile. For a network of four monopiles, and according to the tidal cycle, wakes downstream of the monopile interacted with the other monopiles modifying the current velocity. For the effect of sediment transport, the increase in the flow around the monopile caused resuspension and erosion (scour), while the decrease in the flow generated sediment deposits around the monopile. These effects were in agreement with the ones observed experimentally (in-situ or laboratory) $[25,26]$. This new parameterization may be used to efficiently simulate the hydro-sedimentary changes induced by the monopiles. For other types of foundations, like gravity-based or tripod, results have to be carefully interpreted, and the expressions of the forces need to be adjusted. 


\section{Toward an Ecosystem Approach of Marine Renewable Energy}

Noting that there was no integrated study of the effects of MRE on the ecosystem in the countries where they were implemented $[1,27]$, the $M 2 C$ laboratory promoted a sampling strategy to collect local data for future environmental monitoring programs of OWFs. The $\mathrm{M} 2 \mathrm{C}$ developed an MRE ecosystem approach based on local biomass data (i.e., zooplankton, meiofauna, benthos, and demersal fish) and the link between demersal fish and the benthos, through stomach content studies $[1,27]$. Then, a trophic web model based on these data was built. In parallel, the $M 2 C$, in collaboration with the Biology of Aquatic Organisms and Ecosystems (BOREA) laboratory, explored a new way to understand the potential impacts of OWFs through food web models and flow analysis. They developed an ecosystem-integrated view of the future CSM OWF site to describe the marine ecosystems before OWF construction and to simulate the reef effect after OWF construction (Figure 4) $[27,28]$. Among the different trophic web modeling approaches currently available, the modeling tool Ecopath with Ecosim (EWE) was used [29-31] to describe the initial state of both future OWF sites. This was a mass-balance, zero-dimension modeling approach, which had previously been used to analyze the impact of a wide range of anthropogenic perturbations on marine ecosystems such as fishing, sea dumping operations, new species introductions, and infrastructure development [3237]. However, surprisingly few studies have combined trophic web modeling strength with OWF impact assessment [27, 38]. Thus, the M2C laboratory applied the EwE approach to model the trophic web of the area intended for the CSM OWF and the DLT OWF construction to obtain knowledge of both the systems and to characterize their ecological properties through Ecological Network Analysis (ENA) [1, 27, 28].

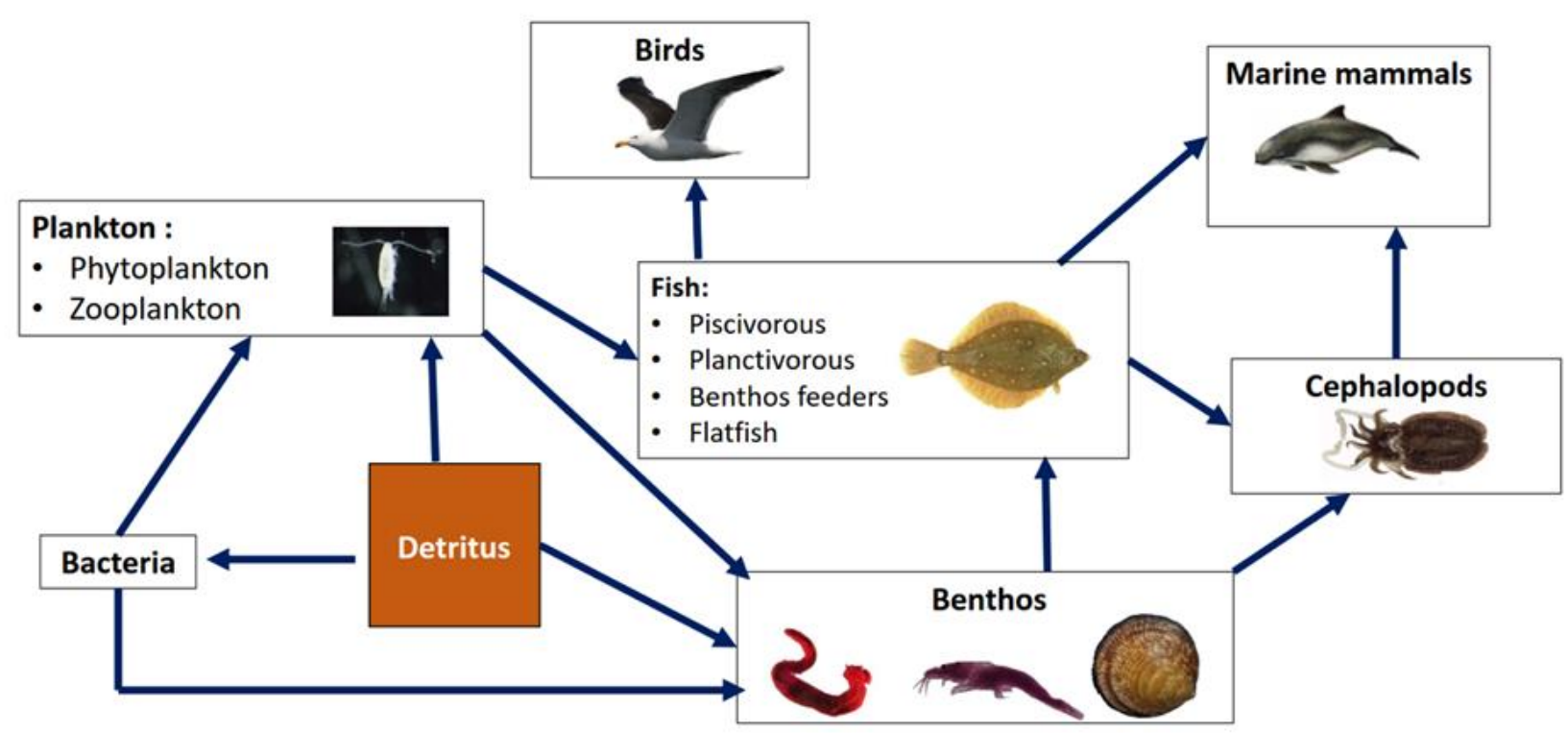

Figure 4 Trophic web of the Courseulles-sur-Mer ecosystem model (modified from Raoux et al., 2017 [27]).

\subsection{Ecopath Models of the Future CSM OWF and DLT OWF Sites}

An ecosystem model composed of 37 compartments (from phytoplankton to seabirds) was built to describe the situation "before" the CSM OWF construction and was called Before Offshore Wind 
Farm (BOWF) [27]. The compartment selection and aggregation were based on trophic interactions. Additionally, special attention was given to commercial species by placing them in monospecific compartments (for more details, see Raoux et al., 2017 [27]). This model was built by using the data collected during the Environmental Impact Assessment (EIA) of the CSM OWF site. The main results highlighted that the CSM trophic web is controlled by an intermediate trophic level dominated by the keystone species, the pouting (Trisopterus luscus). Similarly, an ecosystem model (from phytoplankton to seabirds) was built to describe the structure and function of the DLT OWF construction site. Ecosystem species were grouped into 28 compartments of similar trophic behavior (same prey and same predators). Additionally, benthic invertebrate macrofauna was subdivided into consumed and non-consumed species (more details in Pezy et al., 2018a). This model was built by using the data collected from sampling operations following the methods described by Pezy et al. (2018a) [1]. The main results highlighted that the trophic web is most likely detritus-based and that the ecosystem biomass is dominated by "non-consumed benthic invertebrates". This could be a trophic dead-end for fish due to the size of these filter feeders compared to the size of the fish in the DLT area. All information regarding the input and output parameters of the CSM and the DLT Ecopath models can be found in Raoux et al. (2017) [27] and Pezy et al. (2018a) [1], respectively.

The area intended for the construction of the CSM OWF and the DLT OWF had gravelly sand. The ecosystem biomass of both sites was dominated by benthic invertebrate filter feeders, with biomass of $22.5 \mathrm{gC} \cdot \mathrm{m}^{-2}$ at the CSM site (dominated by the bivalve, Polititapes rhomboides) and $45 \mathrm{gC} \cdot \mathrm{m}^{-2}$ at the DLT site (dominated by the dog cockle, Glycymeris glycymeris, and the banded carpet clam, Polititapes rhomboides) [1, 39]. The comparison of the ENA between the gravelly sand of the OWF planned at CSM and at DLT highlighted that the total activity and ascendency values were higher for the CSM OWF. This was because the CSM OWF model had a greater number of compartments than the DLT OWF model and a higher intake of nutrients from the Seine River [40]. Additionally, between the two sites, the recycling value was higher at the area intended for the DLT OWF construction due to higher bivalve biomass at the DLT site [39]. This result highlighted the importance of considering an ecosystem perspective with physical and biological coupling in the OWF surveys. Thus, even if both these sites had a similar type of sediment, they had different emergent properties that could be explained partly by higher biomass and species richness at the DLT site.

\subsection{Simulation of the Reef Effect Due to the OWF Construction}

The reef effect has been described for epibenthic and demersal fauna as well as for benthopelagic fish (including commercial species) close to wind farm foundations [27, 28, 41-47]. Filter feeders, such as mussels and amphipods, tend to colonize and dominate the vertical structures of the turbines. Benthic predators such as crabs commonly inhabit the base of the foundations, and the scour protections [48]. In the North sea, several fish species (such as the pouting (Trisopterus luscus) and cod (Gadus morhua) have been shown to aggregate around the foundations, possibly because of the enhanced food supplies which could potentially improve their productivity [42-44]. Additionally, studies have also pointed out that the increase in the biomass of filter feeders, such as the blue mussel (Mytilus edulis), on turbines can alter the pelagic primary productivity by reducing the local concentration of phytoplankton $[46,47,49]$. This depletion of phytoplankton and primary 
production affect the benthic and fouling community and is responsible for changes in the functioning of the ecosystem, such as the local biogeochemical cycle [46, 49].

As mentioned previously, so far, there is no holistic study on the impact of the reef effect induced by OWF constructions on entire ecosystems. Hence, as a complementary approach to the traditional impact assessment, the objective of the $\mathrm{M} 2 \mathrm{C}$ laboratory, in collaboration with BOREA, was to develop an integrated ecosystem overview of the reef effect. Thus, an Ecosim model (the temporal dynamic module of EwE) was derived from projecting the evolution of the ecosystem over the next 30 years, after the simulated increase in the biomass of specific benthic and fish compartments associated with the OWF construction. Key findings from these analyses showed that the reef effect is predicted to lead to a detritivore-dominated trophic web [27], which is similar to the hypothesis of Norling and Kautsky (2008) [50]. An increase in the biomass of benthic invertebrates and benthosfeeding fish in response to the reef effect is predicted to attract apex predators, as hypothesized by Lindeboom et al. (2011) [45] and by Reubens et al. [44]), who demonstrated that poutings fed on the macrobenthos produced on the Thornton bank wind turbines in the Belgian part of the North Sea. Additionally, as mentioned previously, colonization of MRE structures by epibenthic communities (mussels and barnacles) can also affect the offshore infrastructure and its performance. Thus, one of the main challenges of the development of MRE is to understand how biofouling affects turbine performance.

\section{Important Gaps within the OWF Environmental Impact Assessment (EIA) Studies}

The EIA considers the sensitivity to potential disruptions of some groups of valuable species without accounting for the links between them [27]. Thus, the effects of the construction of OWFs on the structure and function of the ecosystem remain unclear. There is an urgent need for the OWF EIA to adopt a holistic and integrated view of the ecosystem in their analyses. Additionally, iconic or flagship species are particularly emphasized for their endangered status and popularity among the masses [51]. Thus, monitoring of biological entities other than top predators, particularly within the benthic community (including hard artificial structures), has not yet been sufficiently accounted for $[27,51,52]$. However, several studies have stressed the need to include the benthos within ecosystem monitoring of the MREs [51, 52]. As mentioned below, the reef effect is considered to be the most important impact on the ecosystem with the arrival of new species. It is thus necessary to analyze the evolution of this new hard-substrate community. Additionally, a European review concluded that knowledge of changes in the functioning of soft-bottom benthic ecosystems due to MRE operations is limited and will require hypothesis-driven research combined with ecological modeling. This study also revealed that benthic sensitivity to MRE is higher than previously indicated [51]. Finally, Dannheim et al. (2019) [52] stressed the urgency to integrate benthic research on the MRE impact assessment with scientific approaches at the ecosystem level.

\section{Next steps}

The hydrodynamic of the Alderney Race is very complex, and further research is necessary to understand the physical mechanisms and their impacts on sediment transport and macrofauna. The $\mathrm{M} 2 \mathrm{C}$ researchers are planning to work on the characterization of the current shear and the interactions between waves, current, and turbulence near the bottom. 
Laboratory experiments will be conducted to evaluate the impacts of species on the turbulent flow near the blade and in the wake. These results will be compared to the numerical results acquired by the $\mathrm{M} 2 \mathrm{C}$ researchers.

The reef effect creates important hard-bottom macrobenthic biomasses, but it also increases the availability of prey to higher trophic levels, especially demersal fishes. It will be essential to identify the part of the benthic biomass consumed by fish around the EMR by using stomach content or isotope analyses to construct a more realistic trophic model due to EMR deployments. This approach was proposed by the M2C laboratory for the CSM EMR site simultaneously with the evaluation of the changes in the soft-bottom and hard-bottom communities. The role of the EMR structures as a source for connecting populations of various species with a benthopelagic development began in October 2020 in the framework of a three-year Ph. D. program. This topic involved benthologists and physicians ensuring a multi-disciplinary approach by the M2C laboratory to establish the English Channel as a model for the Megatidal Sea, where humans are highly dependent on the coastal ecosystem, which is under strong environmental forces.

\section{Acknowledgements}

These works were co-funded by the Normandy Region, the group 'Eoliennes Offshore du Calvados', the group 'Eoliennes en mer Dieppe-Le Tréport', the ANR HYD2M project (ANR-10-IEED0006-07), the ADEME Pile\&Tide project, the Interreg IVa France-Angleterre OFELIA project and the CPER Manche 2021 project. We also acknowledge Nathalie Niquil (BOREA, University of Caen), Guiomar Lopez (M2C, University of Caen), Laurent Benoit (M2C, University of Caen), Laurent Perez (M2C, University of Caen), Martial Boutet (M2C, University of Caen) and Feddy Adong (M2C, University of Caen). Results acquired with Ifremer MARS software. The authors acknowledge the Centre Régional Informatique et d'Applications Numériques de Normandie (CRIANN) for providing the computational resources and support.

\section{Author Contributions}

All authors have made a substantial, direct and intellectual contribution to the work, and approved it for publication.

\section{Competing Interests}

The authors have declared that no competing interests exist.

\section{References}

1. Pezy JP, Raoux A, Dauvin JC. An ecosystem approach for studying the impact of offshore wind farms: A French case study. ICES J Mar Sci. 2020; 77: 1238-1246.

2. Dauvin JC. The English Channel: La Manche. In World Seas: An Environmental Evaluation. 2nd ed. Volume I: Europe, the Americas and West Africa. Cambridge, MA: Academic Press Published; 2019. p. 153-188.

3. Halpern BS, Walbridge S, Selkoe KA, Kappel CV, Micheli F, D'Agrosa C, et al. A global map of human impact on marine ecosystems. Science. 2008; 319: 948-952.

4. Lopez G, Bennis AC, Barbin Y, Sentchev A, Benoît L, Marié L. Surface currents in the Alderney 
Race from high-frequency radar measurements and three-dimensional modelling. Philos Trans Royal Soc A. 2020; 378: 20190494.

5. Lopez G, Bennis AC, Barbin Y, Benoît L, Cambra R, Conley D, et al. Surface hydrodynamics of the Alderney Race from HF radar measurements. Proceedings of 13th European Wave and Tidal Energy Conference; 2019 September 1st; Naples, Italy. Paris: Centre pour la Communication Scientifique Directe.

6. Lazure P, Dumas F. An external-internal mode coupling for a 3D hydrodynamical model for applications at regional scale (MARS). Adv Water Resour. 2008; 31: 233-250.

7. Adong F, Bennis AC. Turbulence models for coastal simulation: Application to Alderney Race. Proceedings of 13th European Wave and Tidal Energy Conference; 2019 September 6th; Naples, Italy. Paris: Centre pour la Communication Scientifique Directe. p. 1-8.

8. Bennis AC, Adong F, Boutet M, Dumas F. LANS- $\alpha$ turbulence modeling for coastal sea: An application to Alderney Race. J Comput Phys. 2021; 432: 110155.

9. Tolman HL. User manual and system documentation of WAVEWATCH ${ } I^{\circledR}$ version 4.18. NOAA/NWS/NCEP/MMAB; Technical Note 316; 2014.

10. Bennis AC, Furgerot L, Du Bois PB, Dumas F, Odaka T, Lathuiliere $C$, et al. Numerical modelling of three-dimensional wave-current interactions in complex environment: Application to alderney race. Appl Ocean Res. 2020; 95: 102021.

11. Bennis AC. Final report of the HYD2M project [Internet]. Plouzane: France energies marines; 2020. Available from: http://hyd2m.criann.fr/en/accueil/projet-2/.

12. Foveau A, Dauvin JC. Surprisingly diversified macrofauna in mobile gravels and pebbles from high-energy hydrodynamic environment of the 'Raz Blanchard' (English Channel). Reg Stud Mar Sci. 2017; 16: 188-197.

13. Retière C. Contribution à l'étude des peuplements benthiques du golfe normano-breton. Rennes, France: Université of Rennes; 1979.

14. Michez N, Bajjouk T, Aish A, Andersen AC, Ar Gall E, Baffreau A, et al. Typologie des habitats marins benthiques de la Manche, de la Mer du Nord et de l'Atlantique Version 2. Paris, Fance: Muséum national d'Histoire naturelle; SPN 2015-45; 2015.

15. Gouillieux B, Sorbe JC. Elasmopus thalyae sp. nov. (Crustacea: Amphipoda: Maeridae), a new benthic species from soft and hard bottoms of Arcachon Bay (SE Bay of Biscay). Zootaxa. 2015; 3905: 107-118.

16. Foveau A, Dauvin JC. Elasmopus thalyae (Crustacea: Amphipoda: Maeridae) in high energetic area off the North-west Cotentin peninsula, English Channel. Cah Biol Mar. 2017; 58: 363-366.

17. Foveau A, Pezy JP, Bauxi N, Baffreau A, Bachelet $Q$, Chouquet B, et al. Range extension of the tanaidid Zeuxo holdichi (Bamber, 1990) along the northern coasts of France? Cah Biol Mar. 2018; 59: 329-333.

18. Foveau A, Haquin S, Dauvin JC. Using underwater imagery as a complementary tool for benthos sampling in an area with high-energy hydrodynamic conditions. J Mar Biol Oceanogr. 2017; 6.

19. Rivier A, Bennis AC, Jean G, Dauvin JC. Hydrodynamic consequences of biofouling organisms on marine energy converters. Int J Mar Energy. 2018; 2: 101-109.

20. Robin I, Bennis AC, Dauvin JC, Gualous H. Impact of tidal turbine biofouling on turbulence and power generation. Proceedings of 24e Congrès Français de Mécanique; 2019 August 26th; Brest, France. Paris: Centre pour la Communication Scientifique Directe. pp. 1-12.

21. Rivier A, Bennis AC, Pinon G, Gross M, Magar V. Regional numerical modelling of offshore 
monopile wind turbine impacts on hydrodynamics and sediment transport. Boca Raton, FL: CRC Press; 2015. pp. 807-813.

22. Rivier A, Bennis AC, Pinon G, Magar V, Gross M. Parameterization of wind turbine impacts on hydrodynamics and sediment transport. Ocean Dyn. 2016; 66: 1285-1299.

23. Ganthy F. Rôle des herbiers de zostères (Zostera noltii) sur la dynamique sédimentaire du Bassin d'Arcachon. Bordeaux, Fance: Université de Bordeaux; 2011.

24. Kombiadou K, Ganthy F, Verney R, Plus M, Sottolichio A. Modelling the effects of Zostera noltei meadows on sediment dynamics: Application to the Arcachon lagoon. Ocean Dyn. 2014; 64: 1499-1516.

25. Rogan C, Miles J, Simmonds D, Iglesias G. The turbulent wake of a monopile foundation. Renew Energ. 2016; 93: 180-187.

26. Gunnoo H, Abcha N, Ezersky A. Frequency lock-in and phase synchronization of vortex shedding behind circular cylinder due to surface waves. Phy Lett A. 2016; 380: 863-868.

27. Raoux A, Tecchio S, Pezy JP, Lassalle G, Degraer S, Wilhelmsson D, et al. Benthic and fish aggregation inside an offshore wind farm: Which effects on the trophic web functioning? Ecol Indic. 2017; 72: 33-46.

28. Raoux A, Lassalle G, Pezy JP, Tecchio S, Safi G, Ernande B, et al. Measuring sensitivity of two OSPAR indicators for a coastal food web model under offshore wind farm construction. Ecol Indic. 2019; 96: 728-738.

29. Polovina JJ. Model of a coral reef ecosystem. I. The ECOPATH model and its application to French Frigate Shoals. Coral Reefs. 1984; 3: 1-11.

30. Christensen V, Walters CJ. Ecopath with Ecosim: Methods, capabilities and limitations. Ecol Modell. 2004; 172: 109-139.

31. Christensen V, Walters CJ, Pauly D, Forrest R. Ecopath with Ecosim version 6 user guide. Lenfest Ocean Futures Project. Vancouver, Canada: University of British Columbia, 2008. pp. 1-235.

32. Langseth BJ, Rogers M, Zhang H. Modeling species invasions in Ecopath with Ecosim: An evaluation using Laurentian Great Lakes models. Ecol Modell. 2012; 247: 251-261.

33. Heymans JJ, Tomczak MT. Regime shifts in the Northern Benguela ecosystem: Challenges for management. Ecol Modell. 2016; 331: 151-159.

34. Pezy JP, Raoux A, Marmin S, Balay P, Niquil N, Dauvin JC. Before-after analysis of the trophic network of an experimental dumping site in the eastern part of the Bay of Seine (English Channel). Mar Pollut Bull. 2017; 118: 101-111.

35. Pezy JP, Raoux A, Marmin S, Balay P, Dauvin JC. What are the most suitable indices to detect the structural and functional changes of benthic community after a local and short-term disturbance? Ecol Indic. 2018; 91 :232-240.

36. Raoux A, Baux N, Pezy JP, Balay P, Lesourd S, Dauvin JC. Evaluating ecosystem functioning of a long-term dumping site in the Bay of Seine (English Channel). Ecol Indic. 2020; 115: 106381.

37. Tecchio S, Rius AT, Dauvin JC, Lobry J, Lassalle G, Morin J, et al. The mosaic of habitats of the Seine estuary: Insights from food-web modelling and network analysis. Ecol Modell. 2015; 312: 91-101.

38. Raoux A, Pezy JP, Ernande B, Niquil N, Dauvin JC, Grangeré K. Isotopic analyses, a good tool to validate models in the context of marine renewable energy development and cumulative impacts. Estuar Coast Shelf Sci. 2020; 237: 106690.

39. Pezy JP, Raoux A, Dauvin JC. The environmental impact from an offshore windfarm: Challenge 
and evaluation methodology based on an ecosystem approach. Ecol Indic. 2020; 114: 106302.

40. Billen G, Garnier J, Lassaletta L. The nitrogen cascade from agricultural soils to the sea: Modelling nitrogen transfers at regional watershed and global scales. Philos Trans R Soc Lond B Biol Sci. 2013; 368: 20130123.

41. De Mesel I, Kerckhof F, Norro A, Rumes B, Degraer S. Succession and seasonal dynamics of the epifauna community on offshore wind farm foundations and their role as stepping stones for non-indigenous species. Hydrobiologia. 2015; 756: 37-50.

42. Reubens JT, Degraer S, Vincx M. The ecology of benthopelagic fishes at offshore wind farms: $A$ synthesis of 4 years of research. Hydrobiologia. 2014; 727: 121-136.

43. Reubens JT, Braeckman U, Vanaverbeke J, Van Colen C, Degraer S, Vincx M. Aggregation at windmill artificial reefs: CPUE of Atlantic cod (Gadus morhua) and pouting (Trisopterus luscus) at different habitats in the Belgian part of the North Sea. Fish Res. 2013; 139: 28-34.

44. Reubens JT, Degraer S, Vincx M. Aggregation and feeding behaviour of pouting (Trisopterus luscus) at wind turbines in the Belgian part of the North Sea. Fish Res. 2011; 108: 223-227.

45. Lindeboom HJ, Kouwenhoven HJ, Bergman MJ, Bouma S, Brasseur SM, Daan R, et al. Short-term ecological effects of an offshore wind farm in the Dutch coastal zone; a compilation. Environ Res Lett. 2011; 6: 035101.

46. Slavik K, Lemmen C, Zhang W, Kerimoglu O, Klingbeil K, Wirtz KW. The large-scale impact of offshore wind farm structures on pelagic primary productivity in the southern North Sea. Hydrobiologia. 2019; 845: 35-53.

47. Mavraki N, Degraer S, Vanaverbeke J, Braeckman U. Organic matter assimilation by hard substrate fauna in an offshore wind farm area: A pulse-chase study. ICES J Mar Sci. 2020; 77: 2681-2693.

48. Coates DA, Deschutter $Y$, Vincx M, Vanaverbeke J. Enrichment and shifts in macrobenthic assemblages in an offshore wind farm area in the Belgian part of the North Sea. Mar Environ Res. 2014; 95: 1-12.

49. Maar M, Bolding K, Petersen JK, Hansen JL, Timmermann K. Local effects of blue mussels around turbine foundations in an ecosystem model of Nysted off-shore wind farm, Denmark. J Sea Res. 2009; 62: 159-174.

50. Norling P, Kautsky N. Patches of the mussel Mytilus sp. are islands of high biodiversity in subtidal sediment habitats in the Baltic Sea. Aquat Biol. 2008; 4: 75-87.

51. Wilding TA, Gill AB, Boon A, Sheehan E, Dauvin JC, Pezy JP, et al. Turning off the DRIP ('Data-rich, information-poor')-rationalising monitoring with a focus on marine renewable energy developments and the benthos. Renew Sust Energ Rev. 2017; 74: 848-859.

52. Dannheim J, Degraer S, Jackson AC, Bergström L, Birchenough S, Brzana R, et al. Benthic effects of offshore renewables: Prioritizing the known unknowns. ICES J Mar Sci. 2019; 76: fsz018. 
JEPT 2021; 3(1), doi:10.21926/jept.2101012

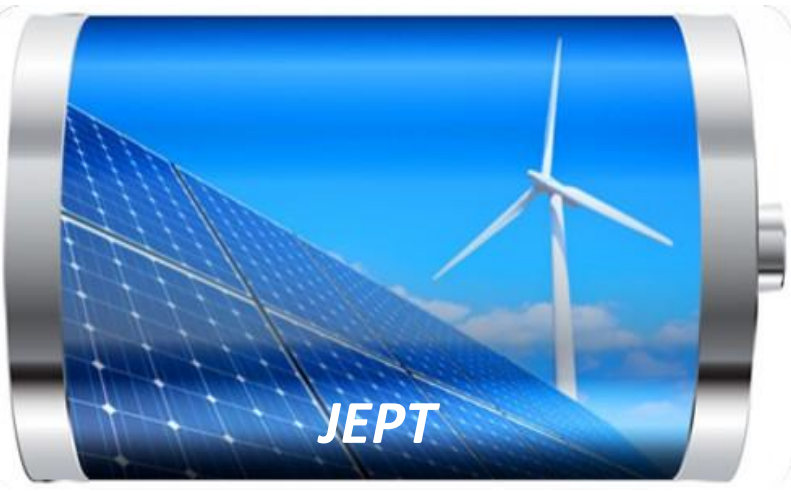

Enjoy JEPT by:

1. Submitting a manuscript

2. Joining in volunteer reviewer bank

3. Joining Editorial Board

4. Guest editing a special issue

For more details, please visit:

http://www.lidsen.com/journal/jept 